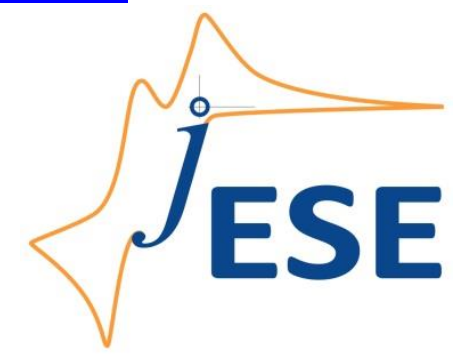

Open Access : : ISSN 1847-9286

www.jESE-online.org

Original scientific paper

\title{
Investigating products of titanium dissolution in the presence of fluoride ions with dual dynamic voltammetry
}

\author{
Noémi Kovács ${ }^{\bowtie}$, Laura Sziráki, Soma Vesztergom, Gyözö G. Láng \\ Department of Physical Chemistry, Laboratory of Electrochemistry and Electroanalytical \\ Chemistry, Eötvös Loránd University, Pázmány Péter sétány 1/A, 1117 Budapest, Hungary \\ Corresponding author's E-mail: ${ }^{凶}$ kovacsnoemi@chem.elte.hu; Tel.: +36-1-372-2500/1527
}

Received: January 15, 2018; Accepted: February 21, 2018

\begin{abstract}
Products of titanium dissolution in the active state are investigated in fluoride containing $1 \mathrm{M} \mathrm{H}_{2} \mathrm{SO}_{4}$ solutions. The novel method of dual dynamic voltammetry, applied to Ti disk/Pt ring rotating ring-disk electrodes, is utilized for the simultaneous detection of different dissolution products. Potential regions where certain products (primarily, Till! and $\mathrm{H}_{2}$ ) are formed are identified by a 3D electrochemical map constructed based on the ring-disk electrode measurements. Besides dissolution in the form of Tilll species and hydrogen evolution, the formation and prompt oxidation of Till can also be presumed under the applied conditions.
\end{abstract}

\section{Keywords}

Rotating ring-disk electrodes; electrochemical map; cyclic voltammetry; dental implant materials; corrosion

\section{Introduction}

Due to its extensive application, the electrochemical stability of titanium has been the subject of investigations for more than fifty years [1-14]. The pure metal itself, and also some of its alloys are widely applied as materials of dental implants and braces. Thus, being aware of the possible dissolution processes of $\mathrm{Ti}$, which can take place in acidic media and in the presence of fluoride ions, is paramount. Assessing the possible corrosion products of $\mathrm{Ti}$ alloys that contain materials with toxic forms is of special importance. Accordingly, the literature of the topic is abundant and continuously expanding [1-22].

In this paper we demonstrate the applicability of a novel experimental method, dual dynamic voltammetry [23-25], for the detection of different dissolution products of titanium. The described technique is applicable to the vast majority of generator-collector systems, in what follows, however, we will concentrate on rotating ring-disk electrodes (RRDEs). 
In conventional RRDE experiments the potential (or the current) of at least one of the two working electrodes is held constant. It was recently shown, however, that independent and dynamic potential programs can also be applied simultaneously to the disk and the ring electrodes [23-26]. By means of dual dynamic potential control, the sensitivity of the RRDE system can significantly be increased, and this control technique also enables the application of several new methods such as the so-called fast ring scanning technique [24]. In this paper, we apply this latter technique for investigating the dissolution of titanium in the presence of fluoride ions.

Since dual dynamic potential control is not feasible by the application of commercially available bipotentiostats, our measurements were carried out by using our self-built measurement station [27]. As it is going to be shown, fast ring scanning experiments on an RRDE can be applied very effectively for studying the dissolution of titanium in acidic media, and in particular, for the detection of different dissolution products.

In order to demonstrate the advantages of this technique, we chose a relatively simple target system: a Ti disk/Pt ring RRDE immersed into $1 \mathrm{M} \mathrm{H}_{2} \mathrm{SO}_{4}$ solutions, containing $\mathrm{F}^{-}$in different concentrations.

Titanium dissolution under similar conditions has been investigated before. Titanium exhibits excellent corrosion resistance in sulfuric acid solutions, due to the easy formation of a highly protective oxide film (mainly $\mathrm{TiO}_{2}$ ). This oxide coating possesses a rather high chemical stability $[2,3]$, preventing the corrosion of the metal. However, researchers seem to agree that fluoride ions, when present in the electrolyte solution, can dissolve the protective oxide layer, exposing fresh titanium surface, and thus destroying the corrosion resistance $[2,4,5]$.

Titanium dissolution in sulfuric acid solutions can also be observed in the absence of $\mathrm{F}^{-}[6-10]$, although at a considerably lower rate compared to $\mathrm{F}^{-}$containing media. Dissolution in the oxidation state of $\mathrm{Ti}^{\mathrm{lV}}$ is likely to occur at positive potentials, in the passive potential region [7], while the formation of $\mathrm{Ti}^{\mathrm{Ill}}$ and $\mathrm{Ti}^{\mathrm{ll}}$ species is supposed to occur at negative potentials, in the active potential region [6]. Till can, however, easily be oxidized in aqueous media, resulting the formation of elemental hydrogen $[6,11]$. At negative potentials, evolution of hydrogen occurs in two parallel paths: one path involves the usual solvated proton and the other involves the adsorbed surface species $(\mathrm{TiOH})^{+}{ }_{\text {ads }}$, followed by a fast recombination reaction [11].

The aim of this work is to present how dual dynamic voltammetry, when used with RRDEs, can allow the simultaneous detection of the different dissolution products of titanium, formed in a broad potential range.

\section{Experimental}

Measurements were carried out with rotating ring-disk electrodes in standard four electrode cells. In all cases, the cell contained a separate reference compartment being connected to the cell by a Luggin capillary positioned close to the RRDE surface. A $\mathrm{NaCl}$ saturated calomel electrode (SSCE) was applied as reference and two glassy carbon rods surrounding the RRDE tip were connected and used as a counter electrode. During the presented measurements the electrode tip was rotated at $500 \mathrm{~min}^{-1}$.

The $1 \mathrm{M} \mathrm{H}_{2} \mathrm{SO}_{4}$ solution was made by dilution of concentrated sulfuric acid (Merck) with Milli-Q water. The fluoride ion containing solutions were prepared by addition of a $1 \mathrm{M} \mathrm{H}_{2} \mathrm{SO}_{4}+$ $+1 \mathrm{M} \mathrm{NaF}$ solution, made from solid NaF (VWR Chemicals). Solutions were purged by and maintained under argon. Measurements were carried out in a water-jacketed glass cell at $37^{\circ} \mathrm{C}$. 
All the glass parts used in the experiments were previously immersed in piranha solution for several hours, rinsed with de-ionized water, and cleaned by steam.

RRDE measurements were controlled by our self-built electrochemical workstation [27]. This system relies on the state-of-the-art data acquisition devices of National Instruments (PCl-4461 and $\mathrm{PCl}-6014$ boards) that can be used in combination with analogue bi-potentiostats. For the measurements presented here, the measuring system was equipped with a PINE Model AFCBP1 bi-potentiostat. The measuring system was controlled by a software written in the National Instruments LabVIEW development environment.

During the experiments we used the following three configurations.

\section{Configuration A}

For the experiments concerning titanium dissolution in $1 \mathrm{M} \mathrm{H}_{2} \mathrm{SO}_{4}$ solution and in $1 \mathrm{M} \mathrm{H}_{2} \mathrm{SO}_{4}+$ + $20 \mathrm{mM} \mathrm{NaF}$ solution we applied a PINE AFE6R1PtPK ChangeDisk rotating ring-disk electrode tip containing a fixed platinum ring $\left(A_{r}=0.1100 \mathrm{~cm}^{2}\right)$ with a PINE AFED050P040 titanium disk $\left(99.999 \%, A_{d}=0.1963 \mathrm{~cm}^{2}\right)$. The gap size between the ring and the disk was $0.75 \mathrm{~mm}$. Collection efficiency calculated from the geometric parameters is $25.6 \%$ [28]. Prior to measurements, the disk and the ring were separately polished by SiC paper and diamond suspension (finest grain size: $1 \mu \mathrm{m}$ ). After polishing, the electrode surfaces were rinsed with pure ethanol and Milli-Q water.

Before recording the presented experiments, the titanium disk was left for 1 hour in $1 \mathrm{M} \mathrm{H}_{2} \mathrm{SO}_{4}$ solution at OCP. Meanwhile, high speed cyclic voltammograms were recorded at the ring in order to clean its surface and to gain a stable baseline CV shape for the collection experiments [24]. After the addition of the fluoride ion containing solution the disk was etched for $15 \mathrm{~min}$ at OCP, then we started to polarize it slowly towards positive potentials. The presented data are results of the first cathodic sweep.

\section{Configuration $B$}

Experiments investigating hydrogen evolution and oxidation on platinum were carried out with the PINE AFE6R1PtPK ChangeDisk rotating ring-disk electrode tip containing a fixed platinum ring mentioned above. Instead of the titanium disk insert, in this case we used a PINE AFED050P040 platinum (99.99 \%) disk. The geometric parameters and the applied polishing procedure were the same as in case of configuration A. Before recording the presented data, high speed cyclic voltammograms were simultaneously recorded the disk and ring electrodes for 1 hour.

\section{Configuration $C$}

For the experiments demonstrating the effect of fluoride ion concentration in the electrolyte we used a fixed "home-made" titanium (99.99\%) disk/platinum ring rotating ring-disk electrode $\left(A_{d}=0.1963 \mathrm{~cm}^{2}, A_{\mathrm{r}}=0.2134 \mathrm{~cm}^{2}\right)$ with collection efficiency of $37.5 \%$, calculated from the geometric parameters [28]. The gap size between the ring and the disk was $0.60 \mathrm{~mm}$. Prior to measurements, the surface of the electrode tip was renewed by lathe machining followed by rinsing with ethanol and Milli-Q water.

The presented measurement series were carried out with step by step additions of fluoride ion containing solution. After every addition step, the titanium disk was etched for $15 \mathrm{~min}$ at OCP before starting the individual measurements. 

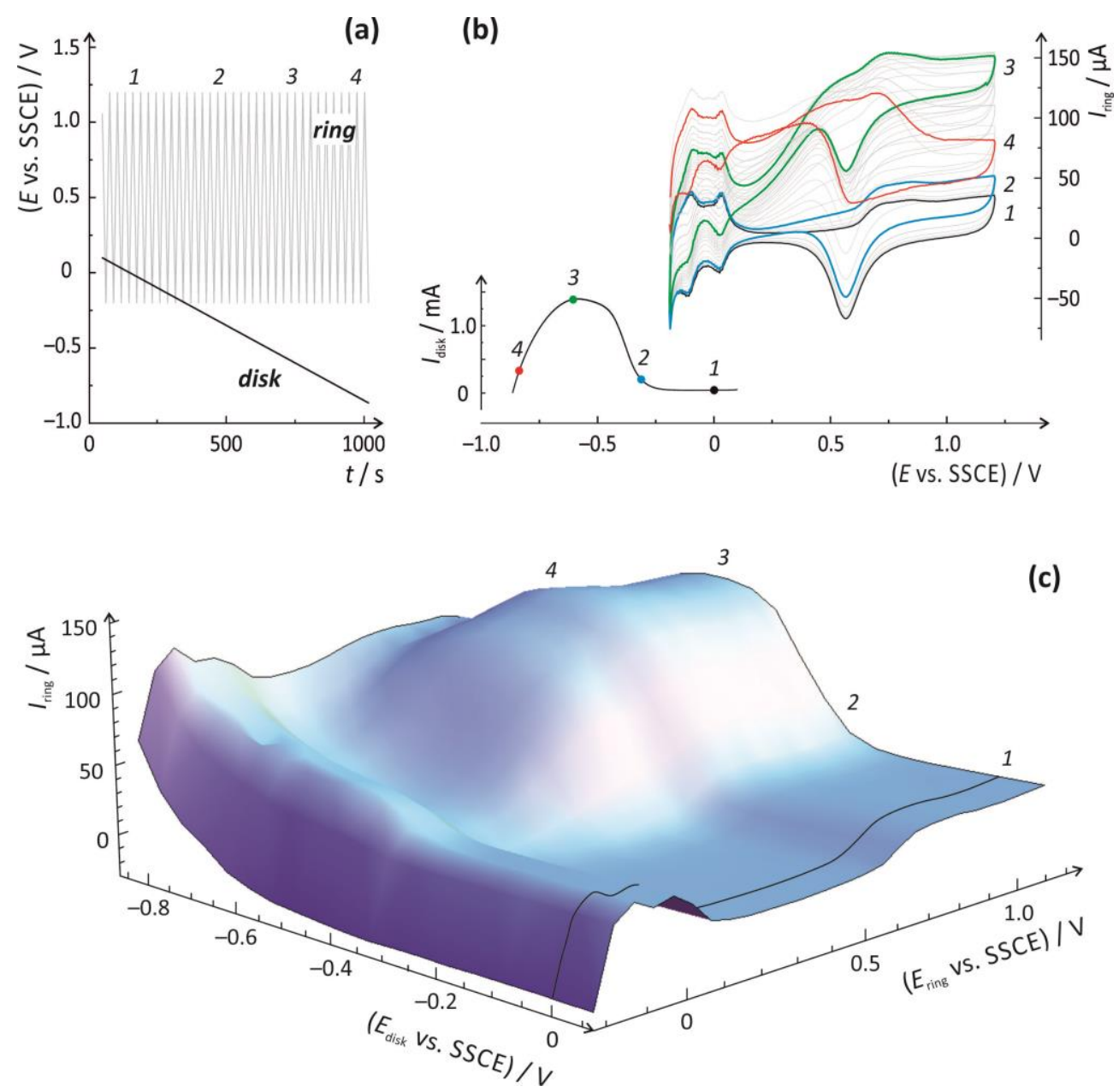

Figure 1. (a) Control signal of the disk and the ring electrodes. While the disk electrode was polarized at a relatively slow sweep rate $(1 \mathrm{mV} / \mathrm{s})$, high speed cyclic voltammograms were recorded at the ring electrode (sweep rate: $100 \mathrm{mV} / \mathrm{s}$ ). (b) Measured current at the disk and

the ring electrodes as a function of the electrode potential. The emphasized cyclic voltammograms on the ring (1-4) were recorded while the disk potential was at the marked values. (c) 3D representation of the measured data created by bilinear interpolation (grid resolution: $50 \times 50 \mathrm{mV}$ ). The current measured on the ring electrode during the anodic ring scans is plotted as a function of the disk and ring potentials, $\mathrm{E}_{\text {disk }}$ and $\mathrm{E}_{\text {ring. }}$.

\section{Results and discussion}

For the investigation of titanium dissolution in the active potential region in the presence of fluoride ions, a special example of dual dynamic voltammetry, the fast ring scanning technique [24] was applied. The essence of this technique is that the disk electrode is polarized at a sufficiently low and the ring electrode at a sufficiently high scan rate. Potential and current data measured this way can be used for the creation of a 3D map that may reveal the electroactive products or intermediates formed in the electrode processes taking place on the disk electrode.

The results of the measurements with a Ti disk / Pt ring RRDE in $1 \mathrm{M} \mathrm{H}_{2} \mathrm{SO}_{4}+20 \mathrm{mM} \mathrm{NaF}$ and the applied potential program can be seen in Figure 1. The disk electrode was polarized at $1 \mathrm{mV} / \mathrm{s}$ sweep rate from $100 \mathrm{mV}$ vs. SSCE, towards negative potentials. At the same time, cyclic voltammograms were recorded at $100 \mathrm{mV} / \mathrm{s}$ on the ring between potential limits of $-200 \mathrm{mV}$ and $1200 \mathrm{mV}$ vs. SSCE. These experiments were carried out using cell configuration A (described in the Experimental section). Due to the hydrodynamic flow created by rotation, the products formed on the disk reach the surface of the ring where the electroactive species can be detected. 
When using fast ring scanning, the current yielded by the detected species is superimposed on a baseline, the cyclic voltammogram of the ring.
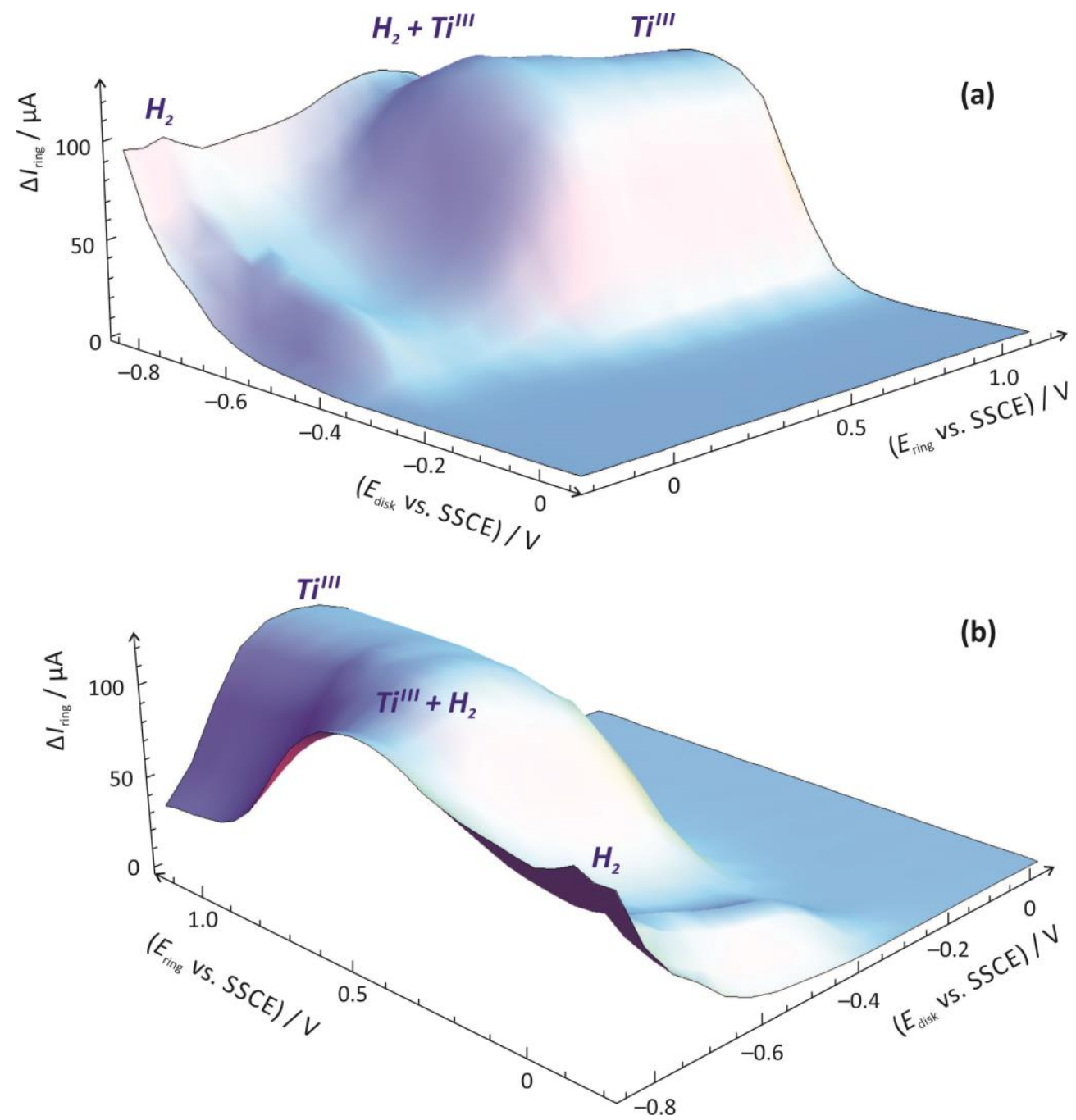

Figure 2. Difference $\left(\Delta \mathrm{I}_{\text {ring }}\right)$ of the ring current and the reference anodic scan ( $\mathrm{E}_{\text {ref, disk }}=O \mathrm{~V}$ vs. SSCE) as a function of $\mathrm{E}_{\text {disk }}$ and $\mathrm{E}_{\text {ring }}$ from two different perspectives: (a) and (b).

In Figure 1(b) it is apparent that the polarization of the disk towards negative potentials results in no significant change of the ring CVs; at least, until no current on the disk is measured (see point 1 on the disk voltammogram in Figure 1(b) and the corresponding ring CV). As the disk current starts to increase (2), the positive potential parts of the ring CVs start to lift and, later on (3), the negative potential parts also start slowly to increase. After the disk current reaches its maximum, the positive potential parts of the ring CVs tend to fall back, while the negative potential parts keep increasing. In order to show all these changes at the same time, a 3D map can be constructed (Figure 1(c)) by means of bilinear interpolation, using the measured disk potential, ring potential and ring current data. For details of the interpolation algorithm, see [29].

The ring scan marked as 1 in Figure 1(c), recorded while the disk was at about $0 \mathrm{~V} v$ s. SSCE, was chosen as reference and subtracted from the 3D map in order to obtain the "surface of changes": the changes measured in the ring currents resulted by the polarization of the disk $\left(\Delta l_{\text {ring }}\right)$ as a function of the disk and ring potentials. Figure 2 shows the electrochemical map constructed in this way from two different view-points. 
For the identification of the peaks on Figure 2, similar measurements were carried out in $1 \mathrm{M} \mathrm{H}_{2} \mathrm{SO}_{4}$ solution with a Ti/Pt, and also with a Pt/Pt RRDE using cell configuration $\mathrm{A}$ and $\mathrm{B}$, respectively. Figure 3 shows the results of these experiments. During the slow cathodic polarization of the platinum disk electrode in $1 \mathrm{M} \mathrm{H}_{2} \mathrm{SO}_{4}$, the evolution of hydrogen starts to occur at suitably negative disk potentials. The hydrogen originating from the disk can be oxidized on the ring electrode, resulting in the changes of the measured Pt CVs, as shown in Figure 3(a).

We note that similar changes in the ring CVs can be measured if we supply hydrogen from an outside source (gas bottle) to the electrolyte. At most potentials, where the platinum surface is active, the collected hydrogen causes an increase of the measured ring current. This increase seems to be independent of the electrode potential of the ring over a broad potential range. When the ring potential is high enough, however, so that the platinum surface is oxidized, the oxidation rate of hydrogen is much slower [30-32]. Thus, the positive potential parts of the ring CVs hardly lift during the experiment.

The situation is rather different in the case when a Ti disk is applied in combination with a Pt ring $\left(1 \mathrm{M} \mathrm{H}_{2} \mathrm{SO}_{4}\right)$. In case of a slow, negative-going polarization, the titanium disk begins to dissolve even in a fluoride-free electrolyte, as a result of a passive-active transition. This is shown by the moderate hump in the polarization curve of Ti, shown in Figure 3(b) at point 2. As a result, a moderate increase of current can be observed at positive ring potentials: an effect that was not present in the case of $\mathrm{Pt}$, and which is due to the collection of $\mathrm{Ti}^{\mathrm{III}}$ species [6]. At more negative potentials (see point 3), hydrogen evolution and slow titanium dissolution take place simultaneously $[6,9]$ and current signals related to hydrogen detection dominate the ring CVs.

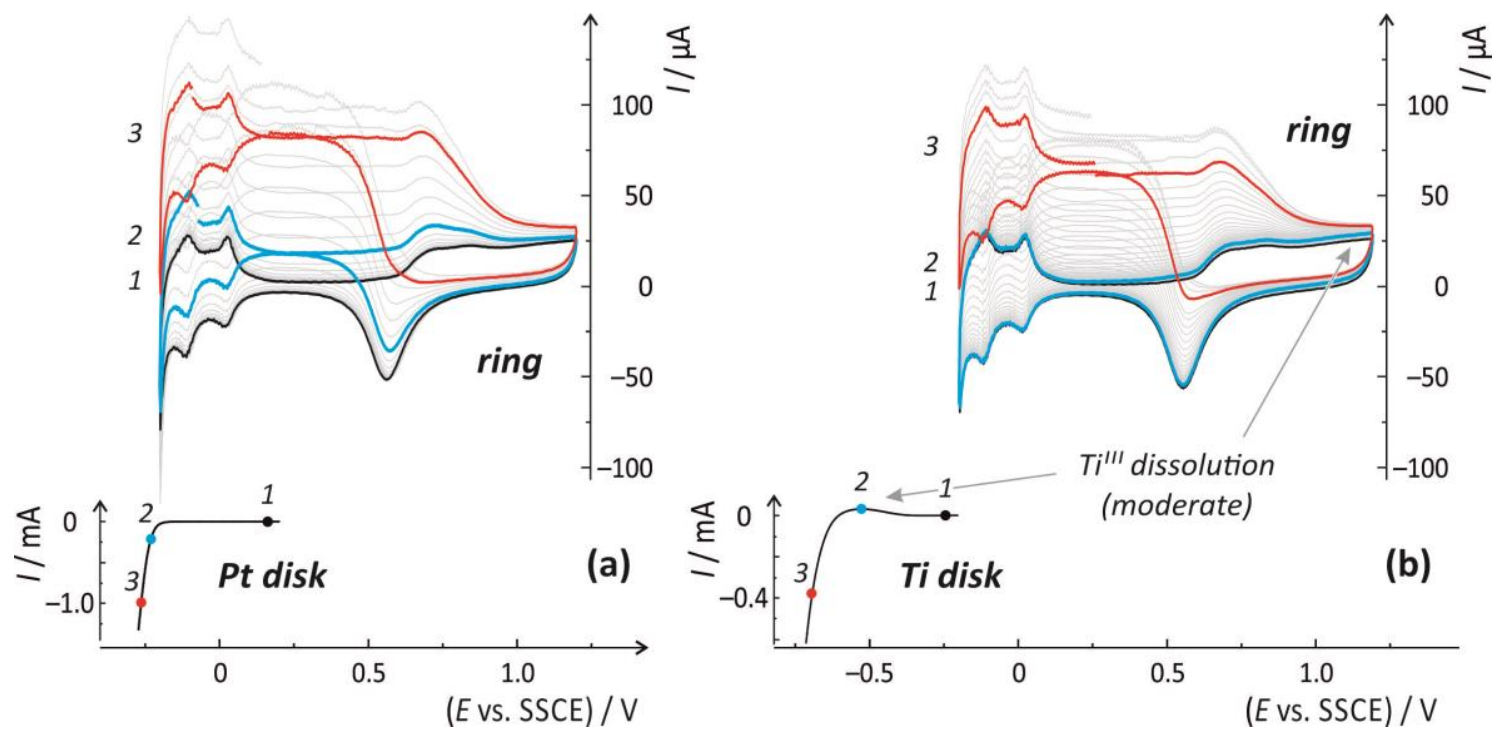

Figure 3. (a) Hydrogen evolution resulted by a slow, negative-going scan on the platinum disk and oxidation of the produced hydrogen on the platinum ring of a Pt/Pt RRDE in $1 \mathrm{M} \mathrm{H}_{2} \mathrm{SO}_{4}$. (b) Slow, negativegoing scan on the titanium disk and oxidation of the formed products and intermediates on the platinum

ring of a Ti/Pt RRDE in $1 \mathrm{M} \mathrm{H}_{2} \mathrm{SO}_{4}$. In both cases the disk electrode was polarized towards negative potentials at $0.25 \mathrm{mV} / \mathrm{s}$ sweep rate while on the ring cyclic voltammograms were recorded between $-200 \mathrm{mV}$ and $1200 \mathrm{mV}$ vs. SSCE at $100 \mathrm{mV} / \mathrm{s}$ scan rate.

Based on the experiments presented in Figure 3, we can come to the conclusion that the lift of the positive potential parts of the platinum CVs in Figure 1(b) and $1(\mathrm{c})$ is caused mainly by the collection of $\mathrm{Ti}^{\mathrm{lll}}$ species formed on the disk, while the lift of the negative potential parts of the ring CVs corresponds to the oxidation of hydrogen. 


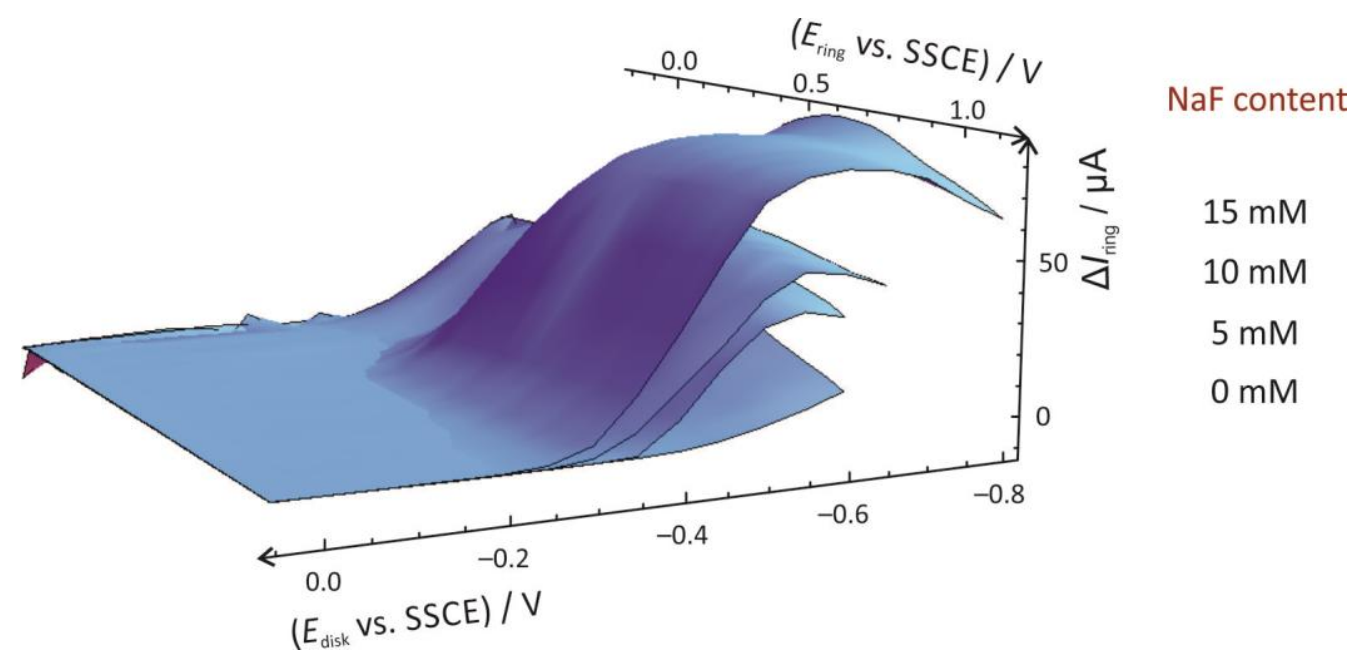

Figure 4. Illustration of the effect of varying the fluoride ion concentration on the detectable ring current changes during fast ring scanning measurements. Measurements were taken in $1 \mathrm{M} \mathrm{H}_{2} \mathrm{SO}_{4}$ solutions containing NaF at different concentrations as indicated. Measurements were taken using configuration $C$, as described in the Experimental Section. A reference disk potential of $0 \mathrm{~V} v \mathrm{vs}$. SSCE was used for creating the presented surfaces.

Here we note that hydrogen detection on the ring electrode may either be a result of direct hydrogen formation or of $\mathrm{Ti}^{\prime \prime}$ production on the disk. As $\mathrm{Ti}^{\prime \prime}$ is unstable in aqueous environments, it is expected to react quickly with water and/or protons to form hydrogen and $\mathrm{Ti}^{\mathrm{III}}$ [11]. Accordingly, at negative disk potentials, $\mathrm{Ti}^{\mathrm{lll}}$ formed as a result of $\mathrm{Ti}^{\prime \prime}$ oxidation may contribute to the Till' collection signal.

It is interesting to note that the 3D surfaces of Figure 2 apparently exhibit three, relatively distinct features. While one of these clearly corresponds to the collection of $\mathrm{H}_{2}$ and another to that of $\mathrm{Ti}^{\mathrm{III}}$ species, the third peak-like feature - based on the results shown in Figure 3- can be attributed to the combined collection of hydrogen and Till species.

In our interpretation, Figure 2 describes the following scheme: while at not very negative potentials, the main dissolution product is $\mathrm{Ti}^{\mathrm{III}}$, at more negative potentials, the disk generates $\mathrm{H}_{2}, \mathrm{Ti}^{\mathrm{Ill}}$ and, probably, also Ti". As $\mathrm{Ti}^{\prime \prime}$ is very unstable in aqueous solutions, it gets oxidized resulting the formation of $\mathrm{Ti}^{11 \mathrm{ll}}$ and additional hydrogen. Note that the ring signal corresponding to Till does not fully decay, not even at extreme cathodic disk polarization (Figure 2(b)). Thus it can be assumed that even at these very negative potentials some $\mathrm{Ti}^{\mathrm{lll}}$ is formed on the disk or that - more likely - the disk generates Til, the subsequent oxidation of which results in the collection of $\mathrm{Ti}^{\mathrm{III}}$ on the ring. In a narrow potential region on the ring, the collection of $\mathrm{Ti}^{\mathrm{Ill}}$ and hydrogen co-occurs, resulting in the peak-like feature marked as " $\mathrm{Ti}^{\mathrm{I}}$ "l $+\mathrm{H}_{2}$ " in Figure 2 (b).

The qualitative interpretation of the measurements, outlined above, remains the same for fluoride concentrations between 5 and $20 \mathrm{mM}$, although the intensity of the ring current signals (the amount of dissolved species) grows in strict correlation with the fluoride concentration. This is shown by Figure 4 and can also be expected based on literature $[5,14]$.

\section{Summary}

By using the method of dual dynamic voltammetry, applied to a Ti disk/Pt ring RRDE, products formed during the polarization of titanium in $1 \mathrm{M} \mathrm{H}_{2} \mathrm{SO}_{4}+20 \mathrm{mM} \mathrm{NaF}$ solution in a broad potential range were simultaneously detected. In the applied fast ring scanning technique, high speed cyclic voltammograms were recorded on the ring electrode while the disk electrode was polarized slowly from the edge of the passive potential region to the active potential region. As a 
result, a 3D electrochemical map of the dissolution products was constructed, giving a comprehensive illustration of potential regions where the different products are formed and where they can be converted electrochemically. Besides dissolution in the form of Till species and hydrogen evolution, the formation and prompt oxidation of $\mathrm{Ti}^{\prime \prime}$ can be presumed under the applied conditions.

Acknowledgements: This work was supported by the ÚNKP-16-3 and ÚNKP-17-3 New National Excellence Program of the Ministry of Human Capacities (ELTE/8495/60(2016) and ELTE/12422/82(2017)). Financial support from the National Research, Development and Innovation Office \& Hungarian Scientific Research Fund (NKFI OTKA K109036) is gratefully acknowledged. S. Vesztergom gratefully acknowledges support from grant NKFI PD-124079 from the National Research, Development and Innovation Office, Hungary.

\section{References}

[1] M. Stern, H. Wissenberg, Journal of The Electrochemical Society 106 (1959) 755-759.

[2] J. J. Kelly, Electrochimica Acta 24 (1979) 1273-1282.

[3] D. J. Blackwood, L. M. Peter, D. E. Williams, Electrochimica Acta 33 (1988) 1143-1149.

[4] M. J. Mandry, G. Rosenblatt, Journal of The Electrochemical Society 119 (1972) 29-33.

[5] Z. B. Wang, H. X. Hu, C. B. Liu, Y. G. Zheng, Electrochimica Acta 135 (2014) 526-535.

[6] R. D. Armstrong, J. A. Harrison, H. R. Thirsk, R. Whitfield, Journal of The Electrochemical Society 117 (1970) 1003-1006.

[7] E. J. Kelly, Journal of The Electrochemical Society: Electrochemical Science and Technology 123 (1976) 162-170.

[8] J. A. Harrison, D. E. Williams, Electrochimica Acta 27 (1982) 891-895.

[9] W. B. Utomo, S. W. Donne, Electrochimica Acta 51 (2006) 3338-3345.

[10] D. Devilliers, M. T. Dinh, E. Mahé, D. Krulic, N. Larabi, N. Fatouros, Journal of New Materials for Electrochemical Systems 9 (2006) 221-232.

[11] E. J. Kelly, H. R. Bronstein, Journal of The Electrochemical Society: Electrochemical Science and Technology 131 (1984) 2232-2238.

[12] W. Wilhelmsen, A.P. Grande, Electrochimica Acta 32 (1987) 1469-1474.

[13] D.-S. Kong, Langmuir 24 (2008) 5324-5331.

[14] M. S. Amrutha, F. Fasmin, S. Ramanathan, Journal of The Electrochemical Society 164 (2017) H188H197.

[15] D. J. Wever, A. G. Veldhuizen, J. de Vries, H. J. Busscher, D. R. A. Uges, J. R. van Horn, Biomaterials 19 (1998) 761-769.

[16] J. E. G. González, J. C. Mirza-Rosca, Journal of Electroanalytical Chemistry 471 (1999) 109-115.

[17] M. Nakagawa, S. Matsuya, K. Udoh, Dental Materials Journal 20 (2001) 305-314.

[18] N. Schiff, B. Grosgogeat, M. Lissac, F. Dalard, Biomaterials 23 (2002) 1995-2002.

[19] A. S. Mogoda, Y. H. Ahmad, W. A. Badawy, Journal of Applied Electrochemistry 34 (2004) 873-878.

[20] B. Lindholm-Sethson, B. I. Ardlin, Journal of Biomedical Materials Research Part A 86A (2008) 149159.

[21] V. A. Alves, R. Q. Reis, I. C. B. Santos, D. G. Souza, T. de F. Gonçalves, M. A. Pereira-da-Silva, A. Rossi, L. A. da Silva, Corrosion Science 51 (2009) 2473-2482.

[22] J. C. M. Souza,S. L. Barbosa, E. A. Ariza, M. Henriques, W. Teughels, P. Ponthiaux, J.-P. Celis, L. A. Rocha, Materials Science and Engineering C 47 (2015) 384-393.

[23] S. Vesztergom, M. Ujvári, G. G. Láng, Electrochemistry Communications 13 (2011) 378-381.

[24] S. Vesztergom, M. Ujvári, G. G. Láng, Electrochemistry Communications 19 (2012) 1-4.

[25] N. Kovács, M. Ujvári, G. G. Láng, P. Broekmann, S. Vesztergom, Instrumentation Science and Technology 43 (2015) 633-648.

[26] S. Vesztergom, M. Ujvári, G. G. Láng, Electrochimica Acta 110 (2013) 49-55.

[27] S. Vesztergom, N. Kovács, M. Ujvári, G. G. Láng, tm - Technisches Messen 84 (2017) 683-696. 
[28] S. Vesztergom, in Reference Module in Chemistry, Molecular Sciences and Chemical Engineering, Elsevier, Amsterdam, Netherlands, 2018, chapter id. 13563-2.

[29] S. Vesztergom, M. Ujvári, G.G. Láng, in Voltammetry: Theory, Types and Applications, Y. Saito, T. Kikuchi, Eds., Nova Science Publishers, New York, USA, 2013, p. 249.

[30] S. Schuldiner, Journal of The Electrochemical Society 115 (1968) 362-365.

[31] J. Bao, D. D. Macdonald, Journal of Electroanalytical Chemistry 600 (2007) 205-216.

[32] A. E. von Mengershausen, N. V. Almeida, M. N. Barzola, J. O. Zerbino, S. M. Esquenoni, M. G. Sustersic, Green and Sustainable Chemistry 4 (2014) 55-59.

(C)2018 by the authors; licensee IAPC, Zagreb, Croatia. This article is an open-access article distributed under the terms and conditions of the Creative Commons Attribution license (http://creativecommons.org/licenses/by/4.0/) 